\title{
منهج تحليل المفاهيم القرآنية
}

\section{هيئة التحرير}

تحليل المفاهيم مبحث مشترك بين اللغة والمنطق وفلسفة العلوم، غير أنَّ فقهاء اللغة يضعونه على قمة أولوياةمم. وواحدة من طرق تحليل المفهوم لديهم هي أن يعودوا به إلى مئل

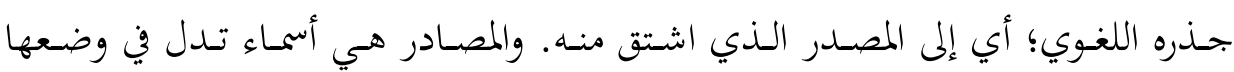
الابتدائي على حوادث تكمن أو تنطلق من الفاعل (مثل قولمم كتب، يكتب، كتابة)،

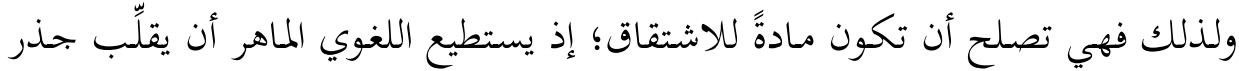

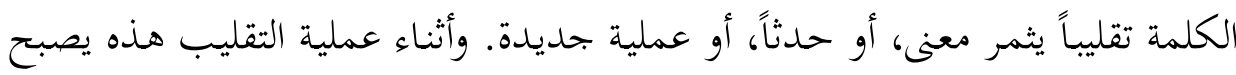

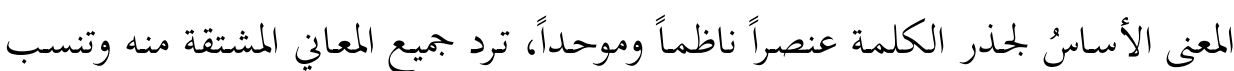

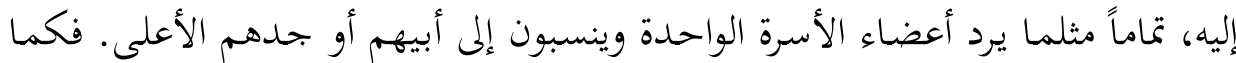

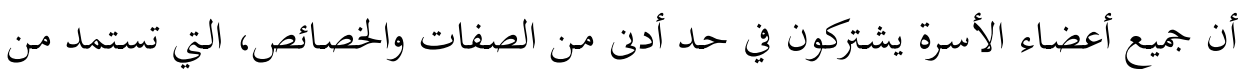

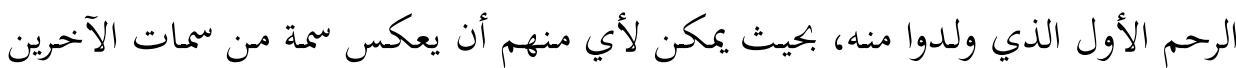

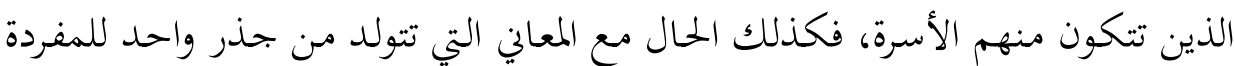
العربية.

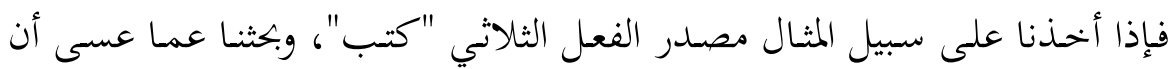

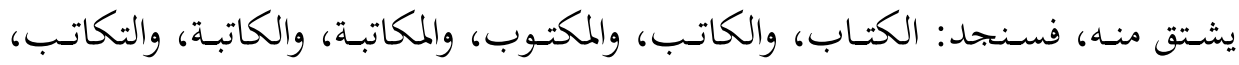

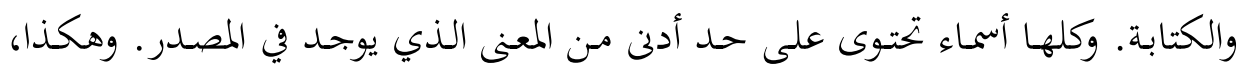

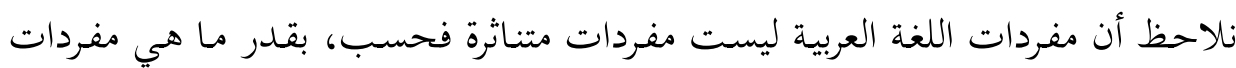

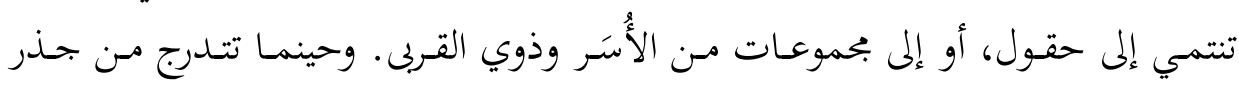

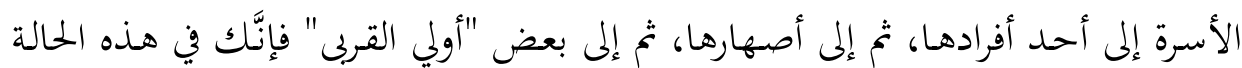

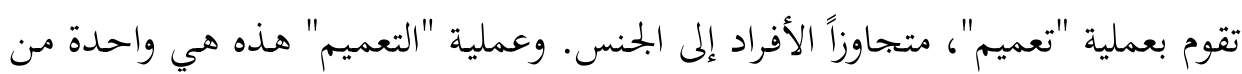


طرائق "صـناعة المفهوم"؛ إذ ينتصـب فيهـا المفهوم جنسـاً عامـاً، تنضـوي تحته جزئيـات

ولكن الإشكال في مثل هذه الطريقة الاشتقاقية أها لا تكون مثمرة مع كل الجلذور

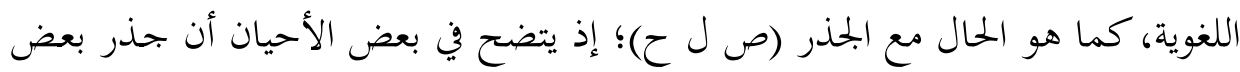

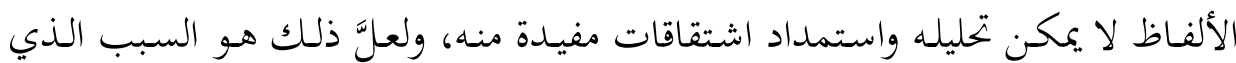

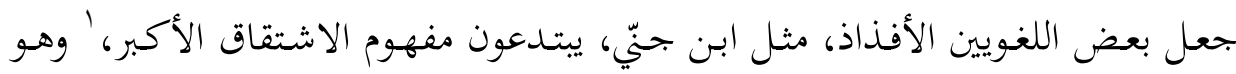

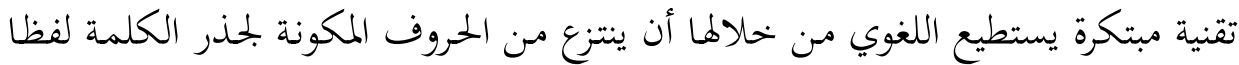
آخر يناسب معناها، ولكنه يزيد عليه بالكشف عن وجوه جديدة منديع من المعاني، أو وجوهاً جديدة من النظر إلى الأفكار والموضوعات.

أمَّا إذا لم تفلح الطريقتان، فإنَّ الباحث سيكون مضطرا لمغادرة نطاق علم الاشتقاق

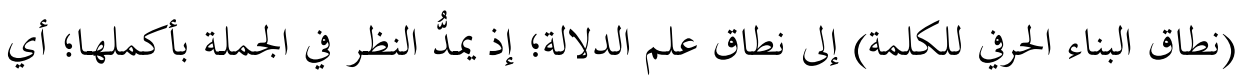

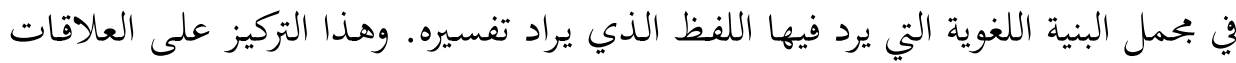

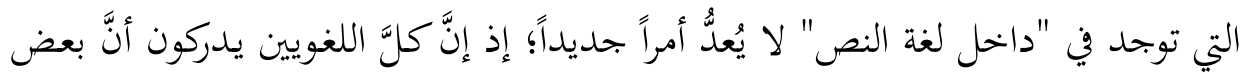
"أبعاد" المعنى يمكن أن تُؤدَّى من خحلال التركيب اللغوي الذي تشارك فيه عناصر لغوية متعددة. وذلك من خصائص الأدب العربي الرصين الذي يعتمد عليه كثير من المفسرين ويستفيدون منه في تفاسيرهم للقرآن.

غير أنَّ هذه الطريقة قد تكون أيضا غير كافية في بعض الأحيان؛ لأنَّ القرآن لا يمثل

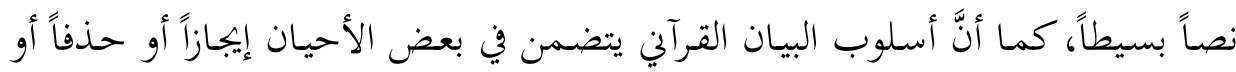

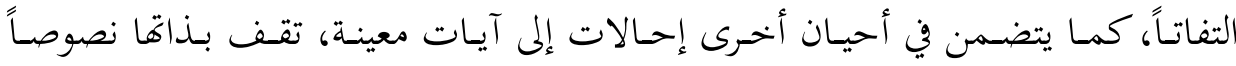

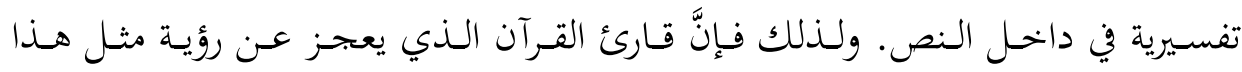

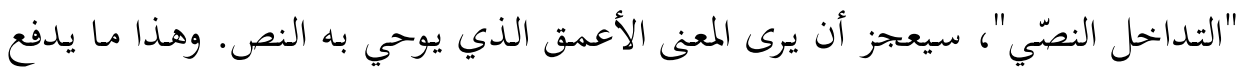

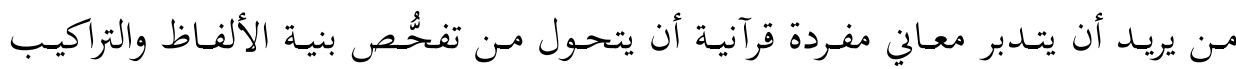
اللغوية (علم الاشتقاق والنحو) إلى تفحُّص البنية القرآنية الكلية.

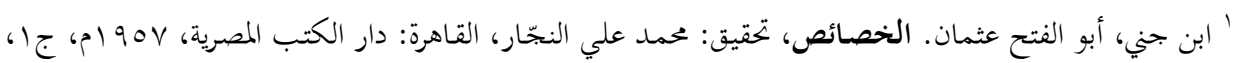




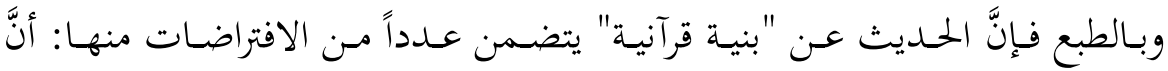

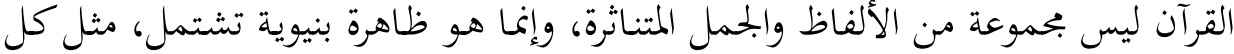

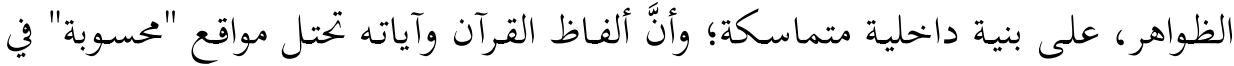

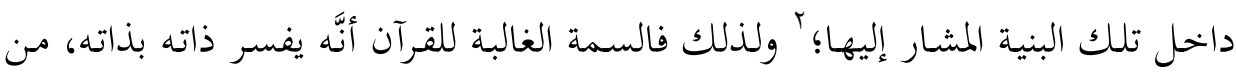

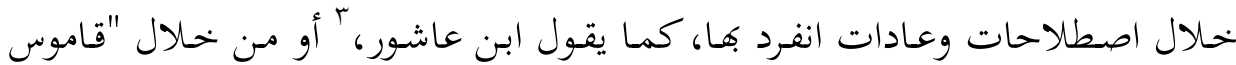

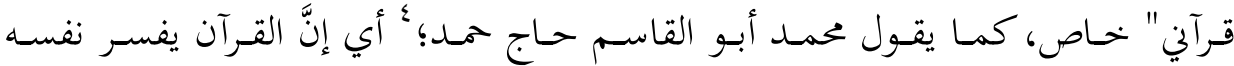

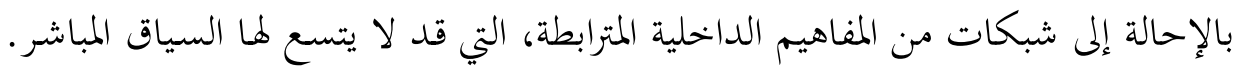

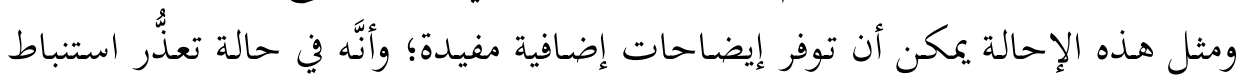

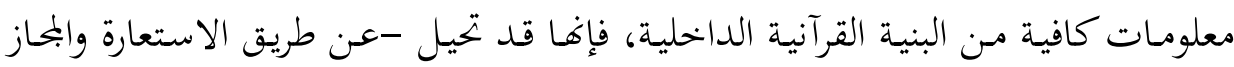

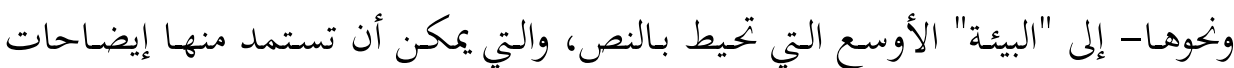

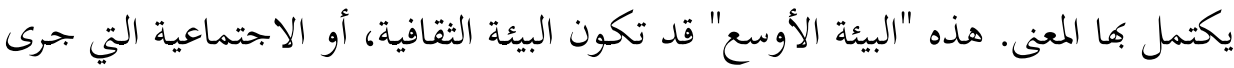
فيها الخطاب، أو البيئة الطبيعية التي تحيط بكما جميعا.

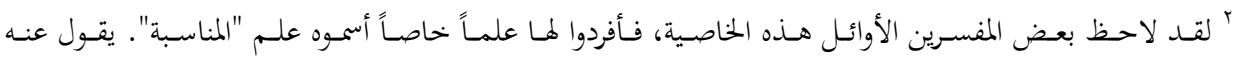

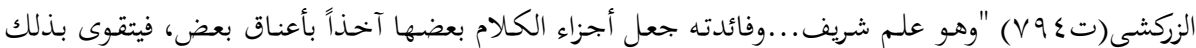

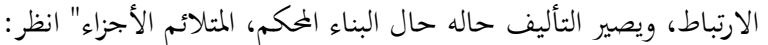

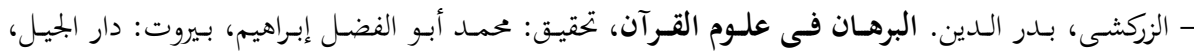

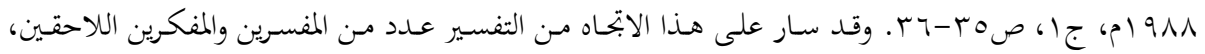

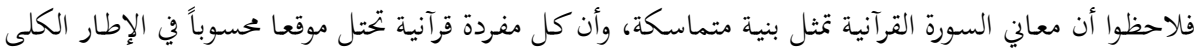

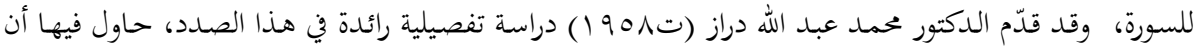

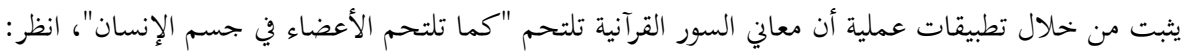

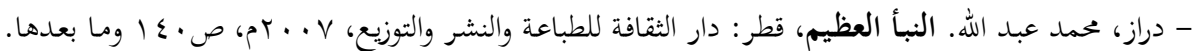

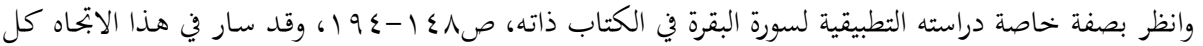

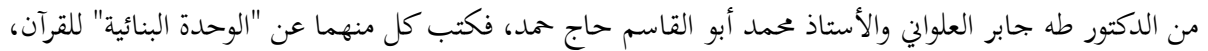

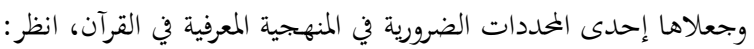

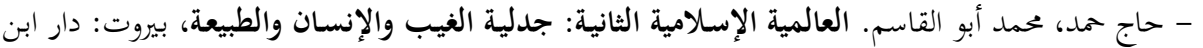

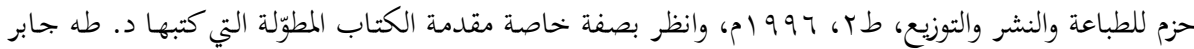
العلوان.

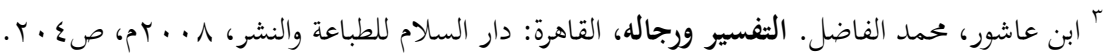

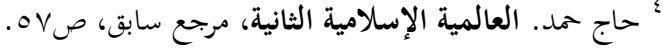


ونحن لا نحاول بتبني هذا المنهج أن نتخطى اللغة، ولكنا لا نريد في الوقت نفسه أن

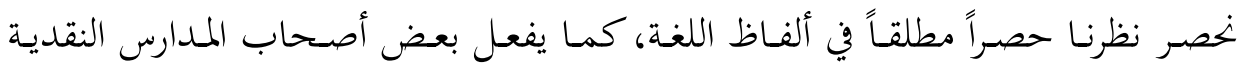

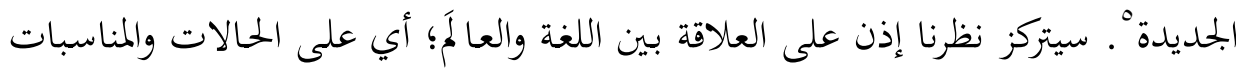
التي يستخدم فيها اللفظ القرآين، وليس فقط على العلاقات اللغوية الداخلية. سنحاول التهال

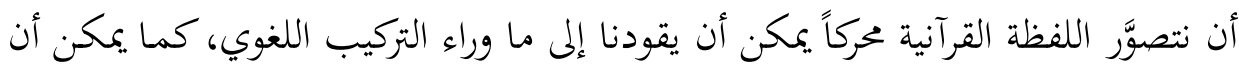

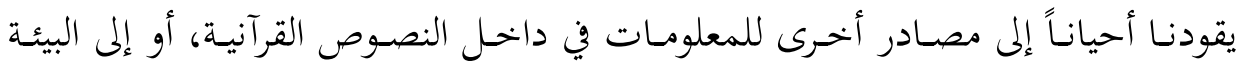

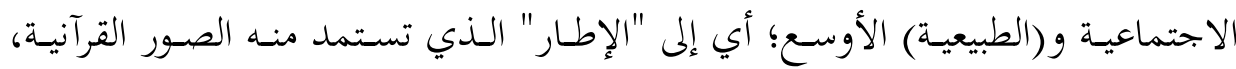
والترابطات والتداعيات التي تسهم في تكوين المفهوم.

إن هذا يمثل على وجه التحديد وظيفة البماز والاستعارة في كل اللغات. فإذا استطعنا

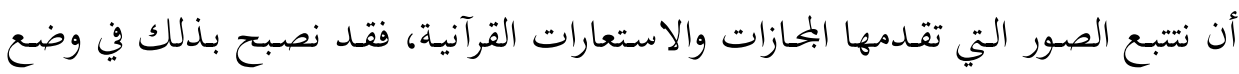
يمكننا من الكشف على النسق التصوري القرآني، وما يتصل به مـن أنساق جزئية مكمّلة

وقد يتساءل القارئ: أنحتاج إلى كل هذا الجههد لنُعرّف معنى لفظ محدد من الألفاظ

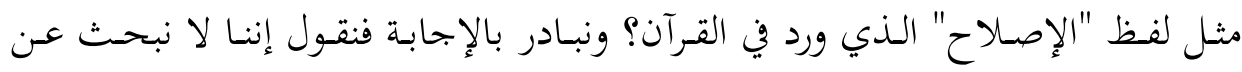

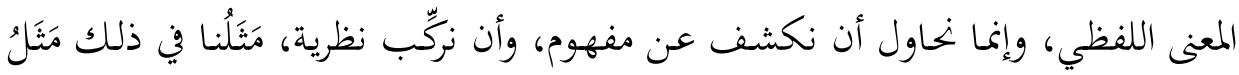

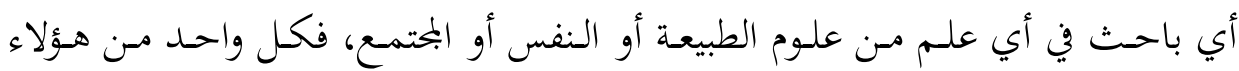

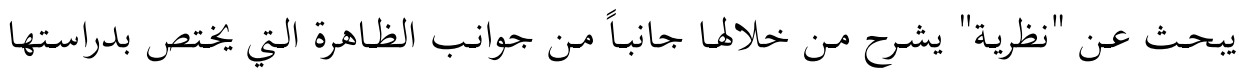

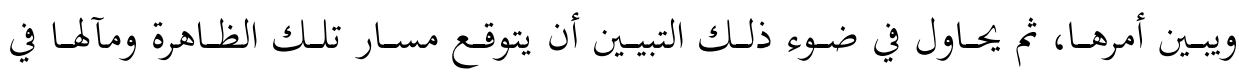

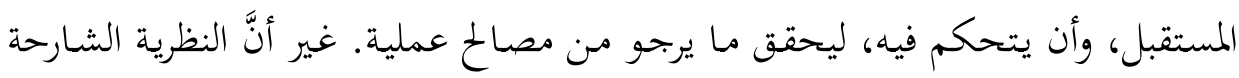

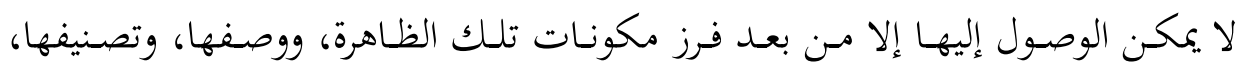

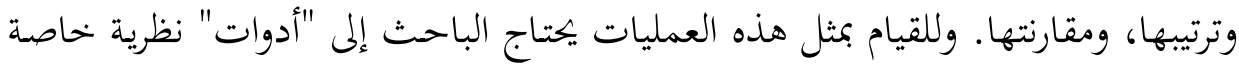

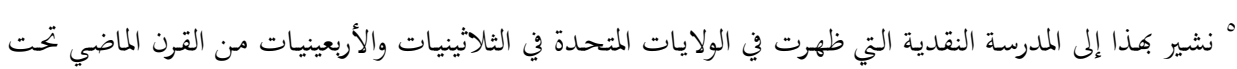

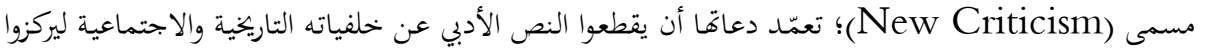
فقط على مادته اللغوية، انظر تفصيلا لذلك في:

- Culler, Jonathan. Literary Theory: A Very Short Introduction, Oxford: Oxford University Press, 1997, p122. 
تعرف بـ"المفاهيم"؛ إذ عن طريق المفهوم يستطيع الباحث أن يصف الظاهرة قيد البحث،

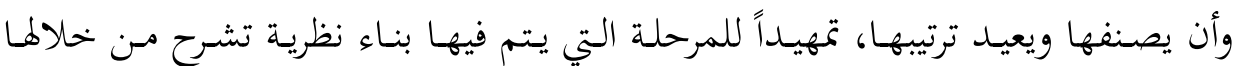
الظاهرة. وغني عن القول إنَّ عملية بناء المفاهيم (من تعريف ونقد وإعادة تعريف) هي تهي الخطوة الأولى التي لا يتقدم علم من دوهنا.

إن مـهنج تحليل المفـاهيم القرآنيـة يلتصق التصـاقاً مباشراً بالبحـث الأول من أبحاث هذا العدد من بحلة إسلامية المعرفة للدكتور التيجاني عبد القادر حامد، حول "الإصلاح

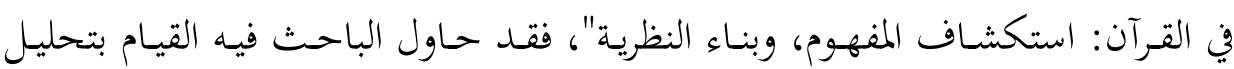
مفهوم الإصلاح في القرآن، ليس على سبيل تمرين في اللغة، بل سعي لاكتشاف المفهوم،

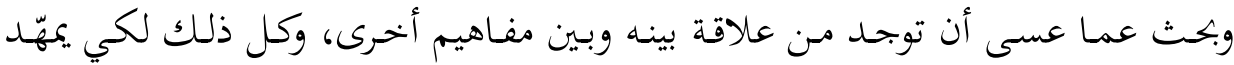

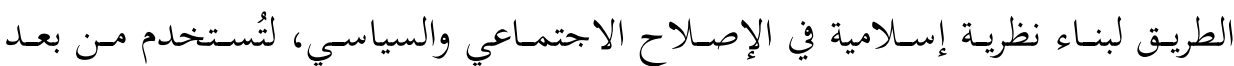
لمراجعة المشروعات التي تطرحها حركات "الإصلاح" المعاصرة وتقويمها، وربما بتحاوزها. لكن مـهنج تحليل المفـاهيم القرآنية يتصل كذلك بـالبحوث الثلاثة الأخرى في هـا

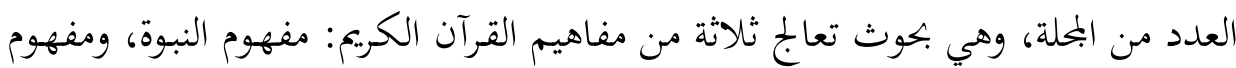
المعجزة، ومفهوم المشترك الإنساني. ففي بحث "النبوة في القرآن الكريم" للباحثين الدكتور

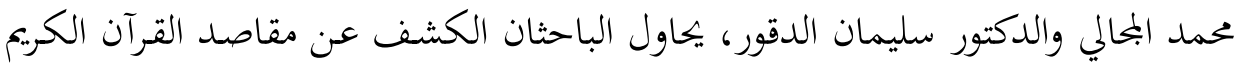
الأساسية في حديثه عن النبوة وأثرها، وبيان أهمية النبوة ودورها في تحقيق صلة إيمان الخلق بالخالق، وإثبات مدى حاجة الناس إلى النبوة في أثرها المتعلق بوحي القرآن والسنة. أما الدكتور جمال الدين الشريف فقد حاول في بحثه المعنون بـ: "المعجزة القرآنية في فكر الجابري" أن ينقد فكر الجحابري في دراسته للمعجزة؛ إذ كشف عن موقف الجابري

" لمعرفة المزيد عن بناء المفاهيم ودورها في بناء النظرية يمكن الرجوع إلى: - Isaak, Alan C. Scope and Methods of Political Science, (Revised ed.) Homewood, IL: Dorsey Press, 1975, pp 63-64. كما يمكن أيضا الرجوع إلي المادة التي أعدّها فريق بحث بتكليف من المعهد العالمي للفكر الإسلامي، ونشرت في :

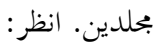
- المعهد العالمي للفكر الإسلامي. بناء المفاهيم: دراسة معرفية ونماذج تطبيقية، تقديع: طه العلواني، وإشراف:

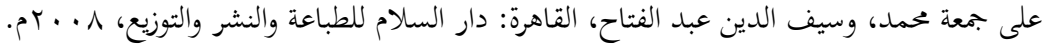




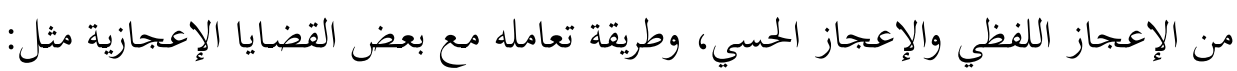

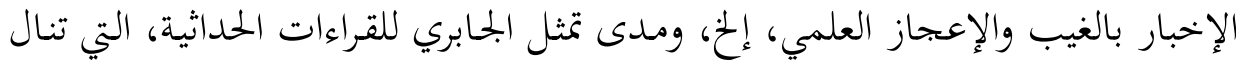

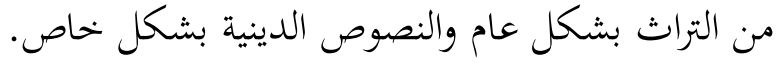

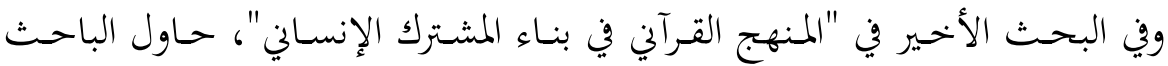

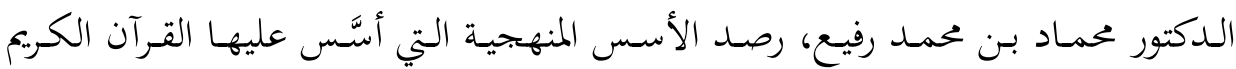

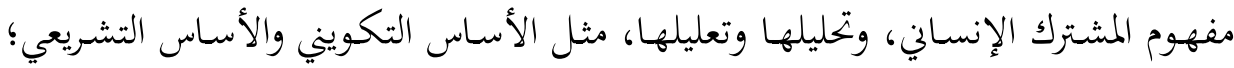

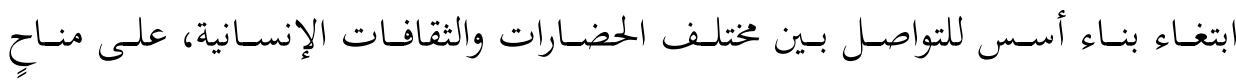

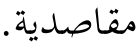

وقد تضمن هذا العدد مـن المجلة إضافة إلى مـا سبق، قراءة لكتاب: "الوجود بين

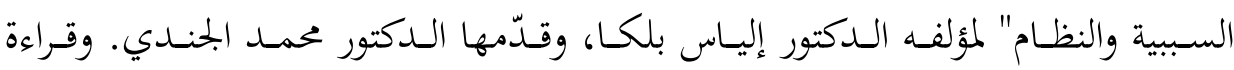

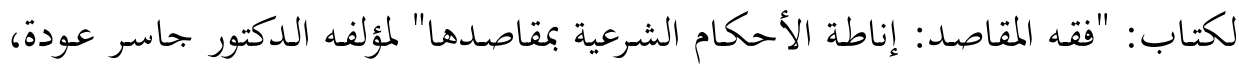

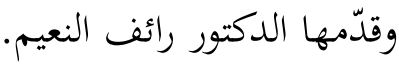
وثمة دعوة استكتاب لمؤتمر الفن في الفكر الإسلامي، وفي العدد حلقة جديدة من عروض غختصرة لعدد من الكتب التي صدرت حديثاً.

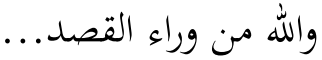

